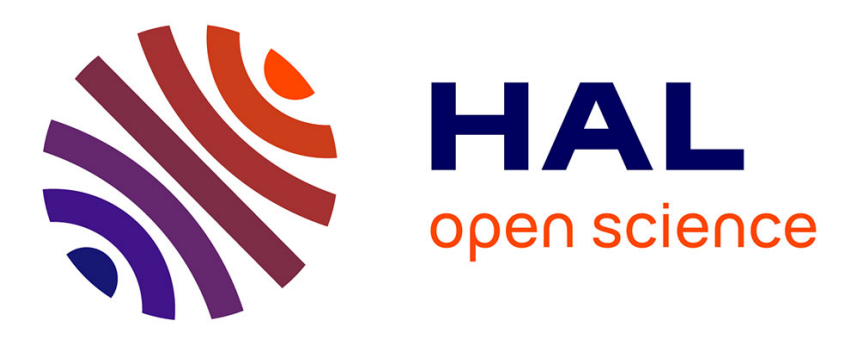

\title{
Near Field UHF RFID Reader Antenna based on Composite Right/Left Handed Structure Compatible with Configurable Reading
}

Romain Siragusa, Etienne Perret

\section{- To cite this version:}

Romain Siragusa, Etienne Perret. Near Field UHF RFID Reader Antenna based on Composite Right/Left Handed Structure Compatible with Configurable Reading. 2019 URSI International Symposium on Electromagnetic Theory (EMTS), May 2019, San Diego, France. pp.1-4, 10.23919/URSIEMTS.2019.8931465 . hal-02886383

\section{HAL Id: hal-02886383 https://hal.science/hal-02886383}

Submitted on 1 Jul 2020

HAL is a multi-disciplinary open access archive for the deposit and dissemination of scientific research documents, whether they are published or not. The documents may come from teaching and research institutions in France or abroad, or from public or private research centers.
L'archive ouverte pluridisciplinaire HAL, est destinée au dépôt et à la diffusion de documents scientifiques de niveau recherche, publiés ou non, émanant des établissements d'enseignement et de recherche français ou étrangers, des laboratoires publics ou privés. 


\title{
Near Field UHF RFID Reader Antenna based on Composite Right/Left Handed Structure Compatible with Configurable Reading
}

\author{
R. SIRAGUSA ${ }^{(1)}$, E. PERRET ${ }^{(1,2)}$ \\ (1) Univ. Grenoble Alpes, Grenoble INP, LCIS, 26000 Valence, France \\ (2) Institut Universitaire de France, 75005 Paris, France.
}

\begin{abstract}
A near field UHF RFID reader antenna based on composite right/left handed is proposed. The ability to generate a steady current when the structure is balanced is used to maximize the read range of UHF RFID tag. A read range of $550 \mathrm{~mm}$ over a surface $240 \times 180 \mathrm{~mm}^{2}$ is obtained with near-field UHF RFID tags $\left(1 \times 1 \mathrm{~cm}^{2}\right)$. The structure is also configurable as the current remains constant whatever the length of the antenna.
\end{abstract}

\section{Introduction}

Ultra High Frequency (UHF) radio frequency identification (RFID) technology has been widely deployed in recent years in the areas of traceability and localization. However, some applications require low ranges and a controlled and scalable reading area. In this case, High Frequency RFID technology where reader and tag antennas operate in the near field is often used. However, the size of the tags at these frequencies, the bit rate, as well as the cost may limit its deployment.

To overcome these problems, the use of UHF RFID in the near-field domain has recently emerged [1]. It allows to have more compact tags (of the order of a $1 \times 1 \mathrm{~cm}^{2}$ ), a high speed and to use the most complete communication protocol of the UHF technology. One of the major problems of UHF RFID near field is to guarantee a large volume of reading, homogeneous and easily controllable. Indeed, in UHF, conventionally used loop antennas are larger than the wavelength. The current vanishes and changes direction along the loop inducing a weak and inhomogeneous magnetic field and thus a reduced reading volume [2]. Two families of antennas are used to solve this problem [3]: segmented resonant loops and nonresonant antennas (TWA). The first solution is to segment the loop antenna to obtain an almost constant current [2]. The design is however complex because of the number of parameters to be optimized and the absence of analytical model. In addition, the playback volume is difficult to reconfigure. The second solution is to use a structure of type transmission line to confine the magnetic field in a given area [4]. The main advantage of this solution is to allow a reconfigurability of the reading area because the operating frequency of the antenna is independent of its length. On the other hand, the reading range is limited to about ten centimeters [4].

In this article, we propose to use for the first time a right hand / left composite (CRLH) antenna [5] with a very particular arrangement, as near field UHF RFID reader antenna UHF. In section 2, we will present this metamaterial-type structure, which has the particularity to have a uniform current. In section 3, we will show how to exploit this particularity to increase the range and reading surface by using a meander configuration. Finally, the performance of the proposed antenna will be compared to a commercial antenna, Impinj CS-778, and a segmented loop in term of read range.

\section{Composite Right/Left Handed near field antenna}

The CRLH transmission lines (TL) are periodic structures usually composed of interdigital capacitances connected to grounded stubs (Figure 1 (a)). The equivalent circuit diagram of the cell is shown in Figure 1 (b). This type of structure has the particularity to exhibit a phase constant $\beta$ equal to zero while having a positive group velocity under the balanced condition $L_{R} \cdot C_{L}=L_{L} \cdot C_{R}$. This condition makes it possible to obtain a constant current along the line because the guided wavelength is then infinite [5].

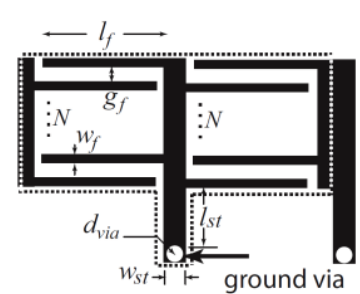

(a) (b)

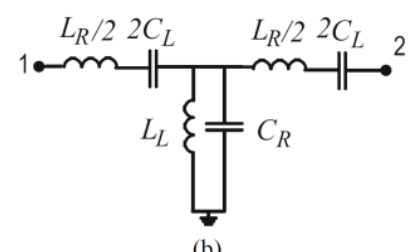

Figure 1. (a) Unit cell of a CRLH transmission line, (b) circuit model of the CRLH unit cell.

Figure 2 (a) shows the balanced 12-cell CRLH line designed with CST Microwave Studio on RT / 5880 substrate of thickness $1.58 \mathrm{~mm}$. The structure has been optimized to have a transition frequency of $915 \mathrm{MHz}$, which is the mid frequency of the US UHF RFID. Figure 2 (b) shows the current along the line at this frequency. We can clearly see that the current is constant along the line while its electrical length is greater than the guided wavelength. Figure 3 shows the magnetic field $H y$ in absolute value in the $\mathrm{XZ}$ cutting plane. With the constant current along the line, the magnetic field is homogeneous. It remains greater than $-20 \mathrm{dBA} / \mathrm{m}$ up to $z=40 \mathrm{~mm}$. This specificity of having a steady current makes it possible to use this structure as an elementary brick to generate any form of constant current sheets as we will present in the next section. 


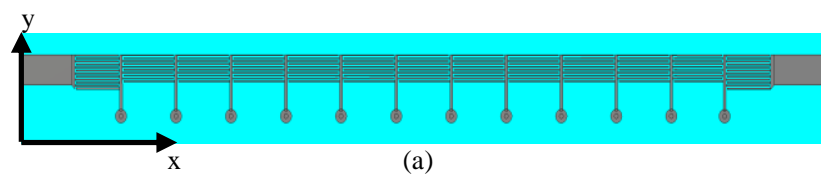

(a)

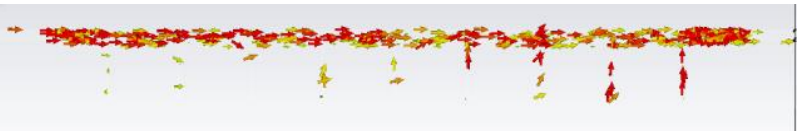

(b)

Figure 2. (a) 12 Unit cell CRLH transmission line (b) surface current at $915 \mathrm{MHz}$ simulated with CST MWS.

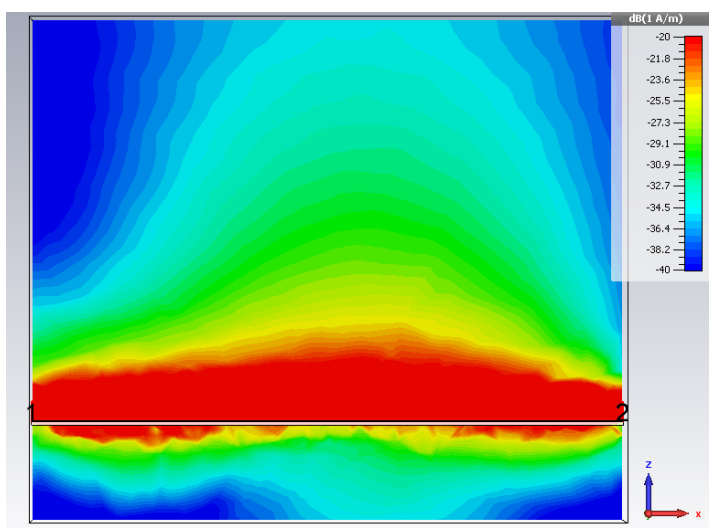

Figure 3. Simulated Magnetic field $H y$ of the 12 Unit cell CRLH transmission line of figure 2 in the XZ plan.

\section{Configurable CRLH Near Field antenna}

\subsection{Theory and simulations}

The balanced CRLH TL has a constant current whatever its length. So it is possible to easily modify the length of the reading zone by increasing the number of cells. To cover a wider surface, it is also possible to juxtapose the lines next to each other. To prove the concept of the configurability of the NF CRLH antenna, we chose to put 6 lines side by side. The elementary line used is the one shown in Figure 2. In practice, it is not possible to have a reader antenna with several power ports. Indeed, the majority of the readers of the trade have only two or four outputs. To overcome this problem, the solution is to connect the $6 \mathrm{CRLH}$ lines by sections of microstrip lines as shown on Figure 4(a). The objective is to obtain a larger reading surface (and so volume) by guaranteeing a constant current oriented in the same direction all along the structure. As the CRLH TL induces no phase shift at the transition frequency $(\beta=0)$, it is necessary to design the sections of microstrip lines to have a phase shift of $\pi$ allowing the current to be oriented in the same direction on the 6 lines. Figure 4(b) shows the current on the meander antenna. We can see that the current is constant on each of the lines and that it is always oriented from left to right thus making it possible to maximize the magnetic field above the structure. Figure 5(a) shows the magnetic field $H y$ above the structure simulated with CST MWS. The field is homogeneous and it remains greater than -20 $\mathrm{dBA} / \mathrm{m}$ up to $z=165 \mathrm{~mm}$. Compare to the structure with one TL, the field strength is higher and may provide a better read range of RFID tag. This ability is mainly due to the fact that the current is constant and in the same direction on the whole structure. Figure 5(b) shows the field when the lines are out of phase. We can clearly see that the field is strongly degraded. The limit of -20 $\mathrm{dBA} / \mathrm{m}$ drop to $45 \mathrm{~mm}$.

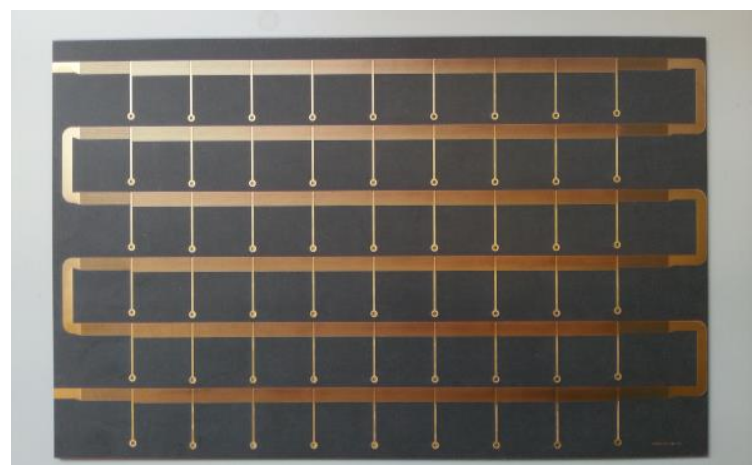

(a)

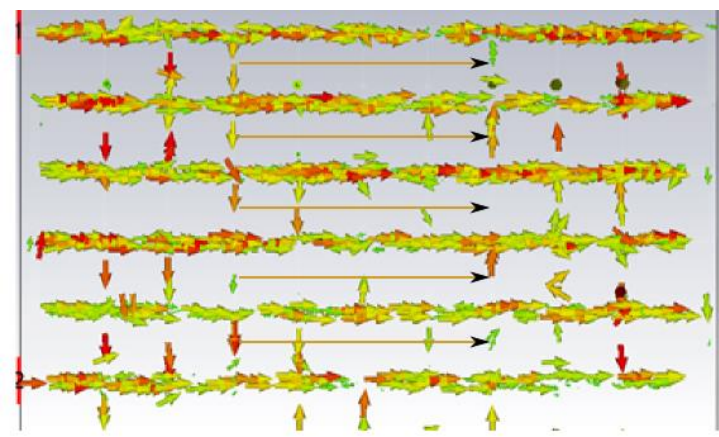

(b)

Figure 4. (a) Meandering arrangement of the near field antenna composed of $6 \mathrm{CRLH}$ transmission lines. (b) Current density of the antenna at $915 \mathrm{MHz}$ simulated with CST MWS.

\subsection{Measurements results}

Figure 6 shows the $\mathrm{S}$ parameters measured with a PNA N5222A. The antenna is well match over the frequency band $[800 \mathrm{MHz} ; 1000 \mathrm{MHz}$ ] that cover the European and the US RFID frequency band. The $S_{11}$ parameter is equal to $-14 \mathrm{~dB}$ at the transition frequency $915 \mathrm{MHz}$ validating that the CRLH structure is balanced. As the CRLH antenna is a transmission line, it is possible to measure the $\mathrm{S}_{21}$ parameter. It is equal to $-4 \mathrm{~dB}$ at $915 \mathrm{MHz}$. Compared to the design of a CRLH LWA, the goal is not to maximize the radiated field. The maximum gain of the antenna was measured at $0 \mathrm{dBi}$ at $915 \mathrm{MHz}$. This low gain allows us to maximize the input power while respecting the UHF RFID standard. 


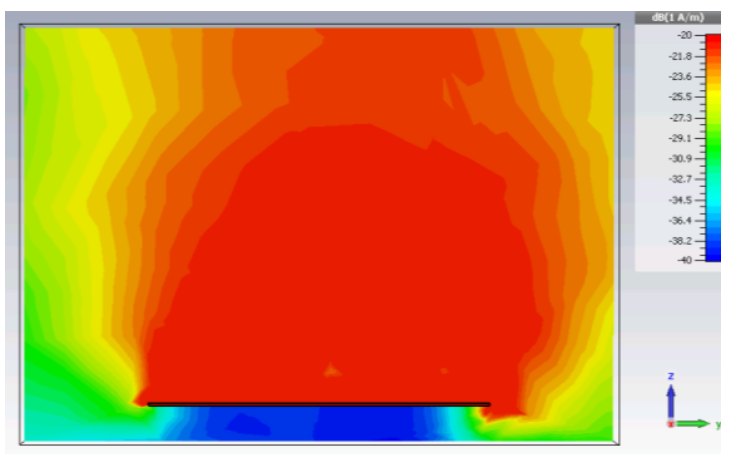

(a)

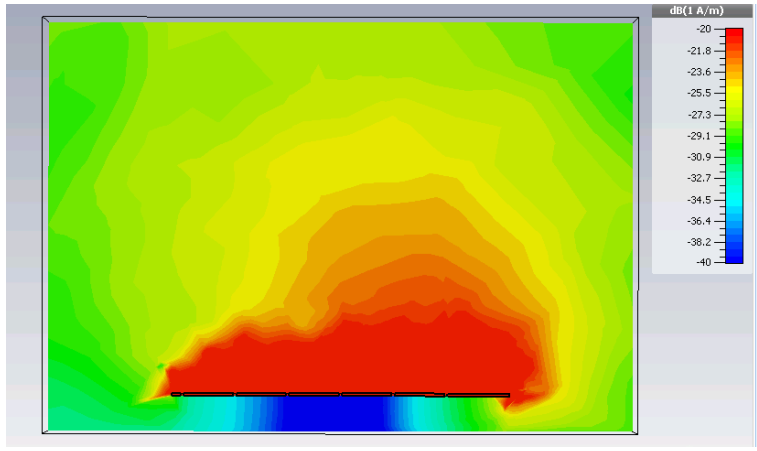

(b)

Figure 5. (a) Hy field of the 6 TL CRLH antenna feed (a) in phase, (b) out of phase simulated with CST MWS.

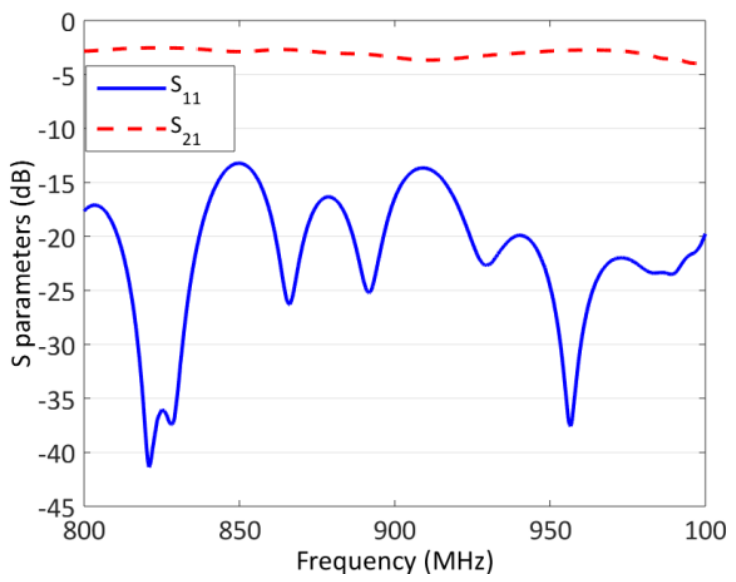

Figure 6. Measured S-paremeters of the 6 CRLH Near Field antenna of Figure 4(a).

To validate the simulation, the magnetic field along $y$ axis of the antenna was measured. The antenna is powered by a sinusoidal signal generator with a frequency of $915 \mathrm{MHz}$ and a power of $5 \mathrm{dBm}$. The field is measured using an ETS-7405 magnetic field probe in the form of a loop. Its role is to transcribe the magnetic field into a voltage measurable with an oscilloscope. To increase the signal level, a low noise amplifier is added in reception. In order to be able to map the field, the probe is placed on an automated three-axis table. Figure 7 shows the normalized $y$ component of the $H$ field measured in the XY plane for $z=100 \mathrm{~mm}$. We can see a good homogeneity of the field on the whole surface of the antenna. The maximum measured field is $-19 \mathrm{dBA} / \mathrm{m}$. It is close to the value obtained in simulation $(-16 \mathrm{dBA} / \mathrm{m})$.

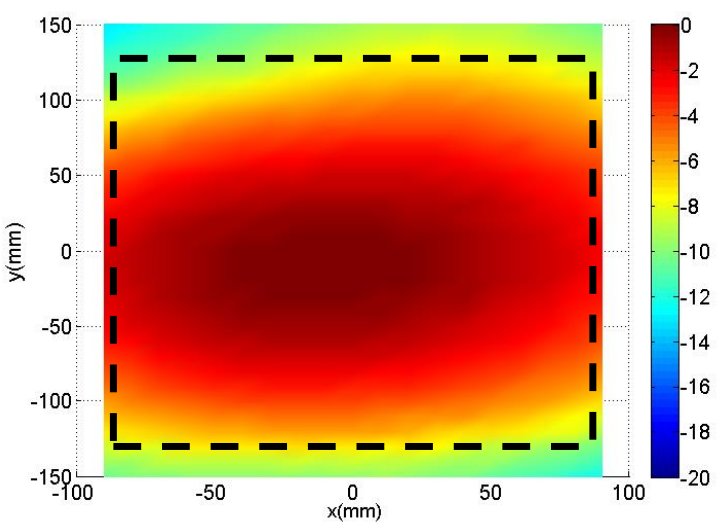

Figure 7. Normalized $H y$ field of the CRLH antenna measured in the XY plan for $z=100 \mathrm{~mm}$ at $915 \mathrm{MHz}$. The dash line show the position of the antenna.

\section{Comparison of the near field antenna performance in term of RFID tag read range}

To evaluate the performance of the CRLH antenna, we have compare the read range of AKtag (a near-field UHF RFID tag $\left.\left(1 \times 1 \mathrm{~cm}^{2}\right)\right)$ using the CRLH antenna, the segmented loop antenna of [2] and the Impinj near field antenna CS778 Brickyard. The AKtag is made of a small loop connected to a Monza chip that can be used as a UHF near field tag. Each antenna is connected to an Impinj Speedway reader. The read range is evaluated using the 3-axis table as shown in Figure 8.

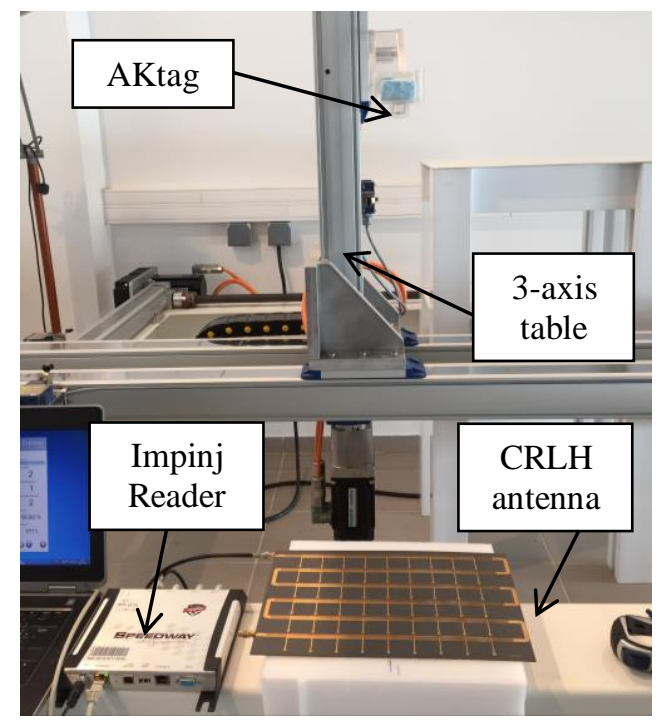

Figure 8. Measurement setup of the read range of the AKtag using an Impinj Speedway reader and the CRLH antenna. The tag is positione using a 3 axes table.

Figure 9 shows the read range of the AKtag using the CRLH antenna, the Impinj CS778 antenna and the segmented loop respectively. For each antenna, the EIRP power was set to $30 \mathrm{dBm}$. The maximum read range for 
the Impinj and the proposed antenna is $550 \mathrm{~mm}$. For both antennas, the read range varies from $520 \mathrm{~mm}$ to $550 \mathrm{~mm}$.

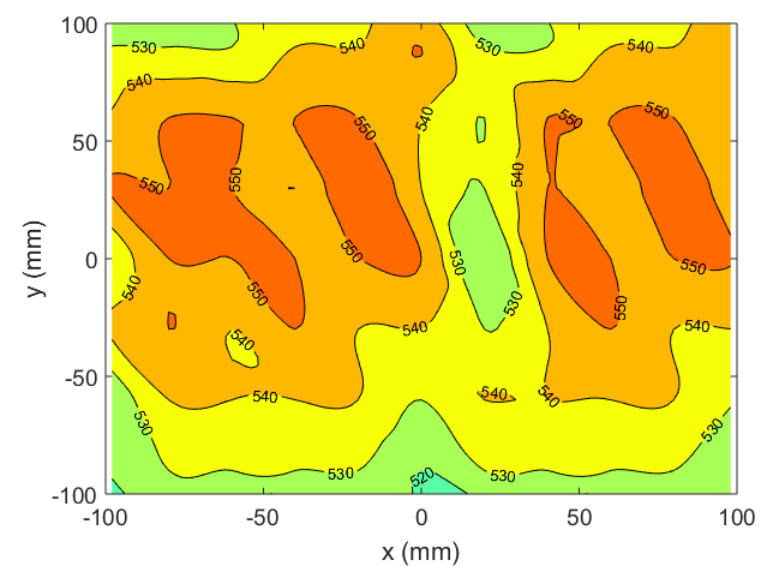

(a)

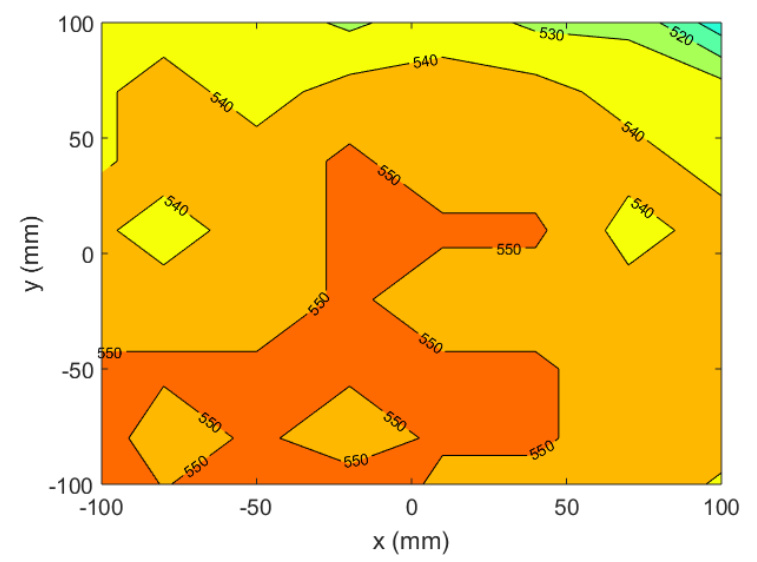

(b)

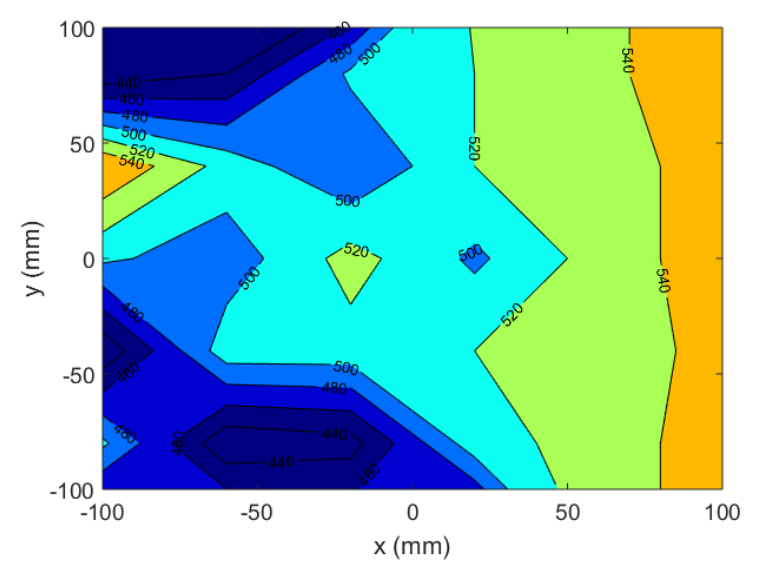

(c)

Figure 9. Read range of the AKtag using an Impinj Speedway reader with (a) the CRLH antenna of Figure 4, (b) the impinj near field antenna CS778 brickyard, (c) the segmented loop of [2] at $915 \mathrm{MHz}$.

The reading is more homogeneous for the Impinj antenna but it is important to notice that it is impossible to modify the volume of reading compare to our antenna. In comparison, the segmented loop has a maximum read rang of $540 \mathrm{~mm}$ but its reading surface is less homogeneous and fall to $440 \mathrm{~mm}$ around the antenna.

\section{Conclusion}

The article presents a near field UHF RFID antenna based on a CRLH type structure. With the meander arrangement and the current control along the line, a reading range of about $550 \mathrm{~mm}$ is obtained on a large and configurable surface using an AKtag with $30 \mathrm{dBm}$ EIRP. This solution has the advantage of being able to configure the reading surface easily by changing the length and the number of CRLH lines. Our proof of concept is polarizing over one axe but it is also possible to control the polarization of the field by changing the orientation of the transmission lines.

\section{Acknowledgements}

The authors thank the Esynov platform of Grenoble Institute of Technology, and Mossaab Daiki for his help in measurement.

\section{References}

1. P.V. Nikitin, K.V.S. Rao, S. Lazar, "An Overview of Near Field UHF RFID," IEEE International Conference on RFID 2007, pp.167-174, 26-28 March 2007.

2. Daiki M., Perret E., Tedjini S., "Antenna Design Method for UHF RFID near field Applications," IEEE International Conference on RFID 2013 , Poster session, 2013.

3. A. Michel, P. Nepa, X. Qing and Z. N. Chen, "Considering High-Performance Near-Field Reader Antennas: Comparisons of Proposed Antenna Layouts for Ultrahigh-Frequency Near-Field Radio-Frequency Identification," in IEEE Antennas and Propagation Magazine, vol. 60, no. 1, pp. 14-26, Feb. 2018

4. A.Michel, R.Caso,A. Buffi,P. Nepa, G. Isola, "Meandered TWAS array for near-field UHF RFID applications," Electronics Letters, vol.50, no.1, pp.17,18, January 22014.

5. C. Caloz, T. Itoh : "Electromagnetic Metamaterials : Transmission Line Theory and microwave Applications", Wiley-IEEE Press, 2006. 